OPEN ACCESS

Edited by:

Paul Robbins,

University of Wisconsin-Madison,

United States

Reviewed by:

Spartaco Gippoliti,

Storia della Fauna, Italy

Zachary Piso,

University of Dayton, United States

*Correspondence:

Pierfrancesco Biasetti

biasetti@izw-berlin.de

Barbara de Mori

barbara.demori@unipd.it

${ }^{t}$ These authors have contributed

equally to this work

Specialty section:

This article was submitted to

Conservation and Restoration

Ecology,

a section of the journal

Frontiers in Environmental Science

Received: 17 July 2020

Accepted: 24 March 2021

Published: 29 April 2021

Citation:

Biasetti P and de Mori B (2021)

The Ethical Matrix as a Tool for

Decision-Making Process

in Conservation.

Front. Environ. Sci. 9:584636. doi: 10.3389/fenvs.2021.584636

\section{The Ethical Matrix as a Tool for Decision-Making Process in Conservation}

\author{
Pierfrancesco Biasetti ${ }^{1,2 *+}$ and Barbara de Mori ${ }^{2,3 * t}$ \\ ${ }^{1}$ Department of Reproduction Management, Leibniz Institute for Zoo and Wildlife Research, Berlin, Germany, ${ }^{2}$ Ethics \\ Laboratory for Veterinary Medicine, Conservation, and Animal Welfare, University of Padua, Padua, Italy, ${ }^{3}$ Department \\ of Comparative Biomedicine and Food Science, University of Padua, Legnaro, Italy
}

Decision making-process in conservation can be very complex, having to deal with various value dimensions and potential conflicts. In fact, conflicts and competing interests between stakeholders are among the most quoted reasons for failure of projects. Ethical analysis can be helpful in this regard. In this paper we present a revision of the Ethical Matrix specifically tailored to decision-making processes in conservation. The Ethical Matrix is a conceptual tool devised to help decision-makers by supplying them with a framework of the ethically relevant aspects involved in decisionmaking process. It was originally developed for the ethical assessment of agri-food biotechnologies and later has been applied to other fields. The revised version we propose here has been designed for the ethical analysis of conservation priority-setting and impact. As conservation can raise many ethical relevant controversies, conceptual tools like the one presented here can be of help for conservationists, providing a map of the value demands involved. This map can be used to question the reasonableness of the value judgments, estimate the impact of different courses of actions, anticipate conflicts, and rank their severeness.

Keywords: ethical matrix, conservation, conservation ethics, decision-making process in conservation, conflicts in conservation, ethical tool, ethical analysis

\section{INTRODUCTION}

Decision making process in conservation can be very complex, having to deal with various value dimensions and potential conflicts. Win-win solutions are usually very rare, and hard choices are normally required (McShane et al., 2011). This, ultimately, may impede conservation. In fact, conflicts and competing interests between stakeholders are among the most quoted reasons for failure of projects (Catalano et al., 2019).

Ethical analysis can be helpful in this regard. Its main goal is to unpack entangled ethical scenarios and map the values involved, exploring the existing possibilities for a fair compromise between differing ethical demands. Conflicts in conservation may be very entangled indeed, and they may involve several interest groups and sources of frictions. For instance, conservation practices, due to the differential social, spatial, and temporal allocation of their costs and benefits, can collide with several human interests (Chan et al., 2007; Vucetich et al., 2018). At the same time, from management of captive populations and field studies (Minteer and Collins, 2005a, 2008) to reintroduction (Harrington et al., 2013) and invasive species control (Littin and Mellor, 2005), 
they may negatively affect the welfare of wildlife animals. Finally, due to hidden value judgments-like, for instance, unfair precedence accorded to certain taxa in priority setting (Amori and Gippoliti, 2000; Krause and Robinson, 2017) — they may even clash with their actual goals.

Even when conservationists are aware of the ethical dimension associated with their work, and of the fact that it can be-and often is-differently perceived from other ethical perspectives (Peterson et al., 2010), a complete map of the value demands involved is still necessary in front of a complex scenario. Such a map, in fact, performs multiple tasks. It could be used to question the reasonableness of the eventual hidden value judgments-and, if necessary, even of the non-hidden ones. To anticipate conflicts, and rank their severeness. To estimate the impact of different courses of actions on different stakeholders. All this, in turn, allows, on the one hand, to establish a better communication and assist with the transparency of the decision making process, and, on the other hand, to design mitigating strategies and possible fair trade-offs, helping fostering the social acceptance of the project. In this paper we present a revised version of an ethical tool devised to help decision makers by supplying them with a transparent and structured frame of the ethically relevant aspects involved in a decision making process: the Ethical Matrix (EM).

The EM was first developed by Mepham (1996) for the ethical assessment of technologies and policies in agriculture and food processing, and has since been applied in other fields, including veterinary science (England and Millar, 2008; Millar, 2013), forestry (Gamborg, 2002), aquaculture (Millar and Tomkins, 2007; Bremer et al., 2015), assessment of humananimal interactions (de Mori et al., 2019; Biasetti et al., 2020), and management of contaminated agricultural ecosystems and radioactive waste (Howard et al., 2005; Cotton, 2009). Our goal here is to provide a revised version of the EM specifically tailored for the ethical analysis in conservation, as this latter is an ethically significant activity because it preserves several sources of value (Biasetti and de Mori, 2016).

\section{THE ETHICAL MATRIX IN CONSERVATION}

The EM (see Table 1) is made up of intersecting columns and rows. Cells from the first column list the stakeholders involved. Cells from the first row list instead the general ethical principles. Every other cell in the EM contains value demands as they are advanced by stakeholders on the ground of the general ethical principles.

\section{Stakeholders}

There is no fixed limit to the number of stakeholders that can be represented in a particular EM. In conservation issues, however, all potential stakeholders come from either one of these three classes:

- Ecological entities-such as biodiversity, biotas, ecosystems, ecological processes, species, populations, etc.
- Animals-meaning the individual members of a species or of another ecological group.

- People-such as local communities, different social or professional categories, people directly or indirectly involved in the conservation efforts, future generations, etc.

As it can be seen, to be a stakeholder it does not matter being capable of personally vindicate a value demand. The EM is in this sense an all-inclusive tool, and it encourages decision makers to take into consideration non-human standpointsto "speak for the wolf"-thus allowing for a comprehensive ethical analysis.

Concerning the two classes of non-human stakeholders it is important to stress a fundamental difference. Kipling's law of the jungle stated that the strength of the pack is the wolf, and the strength of the wolf is the pack. This is not always true from a conservationist's perspective, as conservation practices can in some cases harm individual animals to benefit their taxon or some other aspects of biodiversity. Ecological entities and individual animals stand as separated classes of stakeholders in order to express this fact. It is perfectly possible, then, to have as stakeholders in the same EM both the wolf (species) and the wolves (individual animals), as their value demands could diverge and collide, and, in order to accomplish a comprehensive and transparent ethical analysis, this fact should be recorded.

\section{General Ethical Principles}

The EM espouses a simplified version of the popular approach firstly developed in human medicine bioethics called principlism (Beauchamp and Childress, 1985). This means that its analysis is not structured around a single, influential ethical theory. Instead, the EM tries to account for the moral complexity of the real world by adopting three general ethical principles as cornerstones. These principles are well-being, autonomy, and fairness.

Why these principles? Well-being, autonomy, and fairness are recognized, and shared tenets of ethical reasoning. They mirror the ethical pluralism of common morality, where different angles on values cohabit together (Beauchamp and DeGrazia, 2004; Beauchamp, 2010). While each general ethical principle possess a specific recognizable domain, their content can and need to be contextualized every time they are applied to a scenario. In this way, they provide a broad and flexible frame to describe a large range of situations and values.

The principle of well-being, for instance, can refer to physical and psychological welfare, and be associated with health, functioning, and sentient states like pain, suffering, fear, pleasure and happiness, or it may refer instead to more complex concepts like social and economic welfare. Autonomy can be associated to self-determination, respect for uniqueness, freedom, and individual differences. Fairness is complementary to autonomy: while this latter focuses on the ethically relevant differences, fairness entails the exclusion of all the ethically irrelevant differences from the decision process.

The above are general and abstract statements of the principles. When contextualized, the general ethical principles give raise to a more specific array of value demands. 


\section{Value Demands}

Value demands are specific applications of the general ethical principles to the stakeholders. In other words, they state the ideal requirements to be met in order to respect the stakeholders' well-being, autonomy and fairness.

Value demands are by no means absolute and mandatory: they are, instead, prima facie-meaning with this technical expression that they can be downsized, revised, or even superseded during a balancing process involving other prima facie value demands. In this sense, the filled EM does not provide a list of dos and don'ts, as value demands usually do not form a consistent set, and cannot be met simultaneously. It provides, instead, a complete picture of the moral claims and interests involved before any balancing and trade-off is attempted.

Specific value demands will vary according to the case under scrutiny. However, it is possible to define a basic set of value demands for each class of stakeholders.

(A) Ecological entities. Concerning ecological entities, application of the three general ethical principles concur in fleshing out a multi-dimensional concept of environmental value.

Well-being equates with conservation, further specified according to the biological level occupied by the stakeholder: for instance, maintaining sustainable populations concerning species, preserving richness and variety at all biological levels for ecosystems and biotas, and so on. Given the holistic dimension of ecological entities, interactions and synergies between different levels and components should be considered. Conservation of a keystone species, for instance, should be considered as valuable both per se and for the ecosystem it is part of. On the other hand, conservation of an invasive species outside its native areal should not be considered valuable neither per se, nor for the ecosystem where it has been introduced.

Autonomy embodies here respect for the naturalness of ecological entities-that is, for their separateness from us and our world. This separateness is a fundamental component of many kinds of non-instrumental environmental value (Jamieson, 2008), and should be considered every time we plan an intervention that could make the natural world "less natural." This include not only blatantly negative interventions (such as habitat modification or destruction, logging, mining, poaching, etc.), but also conservation over-management and obstinacy. These latter phenomena happen when we enforce a static ideal on nature, or when conservation efforts are started and continued even if their object is irreversibly compromised, as it cannot be restored or brought again to self-sustainability.

Fairness has to be interpreted as equal treatment in relation to conservation goals. In other words, every level or component of biodiversity deserves to be considered objectively, that is, regardless of our biases grounded on interests and preferences. A vast amount of people, for instance, shows a preference for phylogenetically close and charismatic species, whatever could be their conservation status (Colléony et al., 2017). While certainly legitimate, such a preference, if unconditionally adopted in a decision making process in conservation, would amount to a breach of the fairness principle. Moreover, all components, regardless of our preferences, should deserve a minimum respect for their existence value.

(B) Animals. Concerning individual animals, the three principles work together to shape a multi-dimensional concept of animal welfare (Fraser, 2008).

Well-being involves the first two dimensions: on the one hand, health and functioning, and, on the other hand, absence of negative affective states and allowance of positive ones. Only species considered sentient can be assessed according to this latter dimension of welfare. Health and functioning, instead, can be ascertained for every animal being, regardless of its cognitive capacities.

Autonomy involves the third dimension of animal welfare, that is, living natural lives and exercising species-specific behaviors. These may be defined as the behaviors an animal would have the tendency to exhibit under natural conditions because they promote pleasure, biological functionings, or both (Bracke and Hopster, 2006). "Natural" is, in this sense, a necessary yet not sufficient condition, as some natural behaviors-like reactions to sickness or threat of predation-do not correlate with positive welfare. Similarly, species-specific does not mean "species-exclusive," as many natural behaviors conducive to positive welfare-like walking, or playing-are cross-specific. Freedom to act according with these natural dispositions is an important component of animal welfare (Rollin, 2006), and has to be understood both in a negative and in a positive sense. That is, the animal must not only be free from external constraints that would prevent it, in absence of real needs, to exhibit its speciesspecific behaviors. It must also live in a properly calibrated context to perform them.

Fairness has to be understood here as equal treatment in relation to welfare. This has two implications. The first is that we should assess the welfare of an animal without biases grounded on preferences and interests relative to its species. The second implication is that, all other things beings equal, we should consider the welfare of a particular animal no less important than that of the other individuals of its taxon or of other taxa with similar welfare requirements.

(C) People. Concerning people, well-being equates with the psychological and physiological welfare of individuals, and with the sustainable social, economical, and cultural welfare of communities.

Autonomy can have many manifestations. On an individual level it has to be understood as freedom of choice. Moreover, it is also the capacity to exercise the various fundamental aspects of one's own persona: one's profession, culture, traditions, etc. On a community level it equates instead with self-determination. It is important to note that autonomy entails both negative and positive obligations, going in this sense beyond mere noninterference (Beauchamp and Rauprich, 2016). The requirements for autonomous action are not limited to the possession of freedom of choice, but assume instead the possibilities of informed and responsible action. In this way, respect for autonomy is strictly related with providing the stakeholders with complete and reliable information in order to protect their free agency. 
Fairness involves equal and fair treatment of individuals, institutions, and communities, avoiding biases grounded on personal preferences or inclinations, partisanship, prejudices, and so on. This includes also fair distribution of costs and benefits concerning the conservation projects analyzed.

\section{The Ethical Frame of the EM}

A merit of the EM is to adopt ethical pluralism as a starting point for analysis. The advantages of this methodology are several. Pluralism is more effective in grasping the subtleties of real contexts of decision-making than theories based on a single general ethical principles, or on a hierarchical or otherwise coherent set of principles. Through a pluralist approach it is possible to reconstruct the different moral angles that can be taken on the same issues, and grasp the interests of various kinds of stakeholders. Moreover, by providing a complex analysis of a given scenario, pluralism permits, on the one hand, to include peripheral and even marginal value demands, and, on the other hand, to highlight eventual limits and parochialism of more resounding ones.

The pluralism entailed by the principlist approach, however, does not equate with moral relativism (Beauchamp and Rauprich, 2016). The ethical perimeter sketched by the EM has definite borders which provide a solid backbone to the analysis.

Table 1 recap the value-demands embedded in this version of the EM calibrated for conservation. There are two main ideas behind this configuration. The first is that the ethics of conservation is a specific, non-reducible, and multidimensional field of applied and professional ethics, which encompass and intersect several value-contexts and issues (Minteer and Collins, 2005b; Biasetti and de Mori, 2020). The second is that the most characterizing feature of this field is that it poses several ethically significant desiderata which cannot often be satisfied at the same time. Its "hard problem," in this sense, is finding acceptable criteria for ordering these desiderata, and avoid ethical stall.

The EM does not offer a direct solution to this hard problem, but can assist by listing in an organized frame the values involved. These are individuated and regrouped according to three fundamental poles of aggregation: the environmental, the animal, and the human. Pushing forward on the pluralist premise, each of these poles of aggregation is constructed in order to reflect the various ethically significant facets it can assume.
Environmental value, for instance, is defined in the EM in order to encompass the different ways and reasons through which it is possible to value biodiversity, nature, and the environment. Starting from the principle of well-being, for instance, it is possible to accommodate reasons for conserving biodiversity either from a non-anthropocentric perspective (Callicott, 1989; Batavia and Nelson, 2017; Piccolo et al., 2018) or from an instrumental perspective based on enlightened or prudential anthropocentrism (Norton, 1991; Reid et al., 2006; Justus et al., 2009) - or, even better, from a much longed-for integration of the two (Tallis and Lubchenco, 2014).

Similarly, the principle of autonomy permits to include into the ethical analysis the concept of naturalness. This latter is important for a third family of environmental values, anthropocentric yet not instrumental-for instance, aesthetic, epistemic and reverential values (Biasetti and de Mori, 2016), or eudaimonic (relative to the "good life") relational values (Chan et al., 2016). These require the possibilities for an authentic relationship with nature, and, as such, depend on the genuine quality of the naturalness of an environment-that is, on its autonomy from human intervention.

Finally, the principle of fairness accounts for the elimination of eventual bias. Preference for "charisma," for instance, may be detrimental to conservation. It may be the cause for inefficient allocation of resources (Mammola et al., 2020), or, as the story of the attempted eradication of the gray squirrel (Sciurus carolinensis) in Italy (Bertolino and Genovesi, 2003) shows, it may support invasion from non-indigenous species and overall biodiversity homogenization (Jarić et al., 2020). In the end, charisma may even be detrimental to charismatic yet endangered species, as it foments a false impression of abundance in species that are actually in decline (Courchamp et al., 2018).

Applying fairness across different components of biodiversity does not entail, however, that there should be no valid criteria in conservation priority-setting. Consequentialist reasons, if grounded in sound conservation science, are still compatible with application of the principle of fairness. In this sense ecological criteria-keystone species status, for instance-would still be acceptable.

The pluralistic approach embedded in this revision of the EM is adaptable and robust enough to grasp the various aspects of environmental value. Similarly, in this EM animal ethics is dealt with by taking into consideration different aspects of animal welfare-from the physiological to the behavioral,

TABLE 1 | General template for the EM in conservation.

\begin{tabular}{|c|c|c|c|}
\hline & Well-being & Autonomy & Fairness \\
\hline Ecological entities & Conservation & Freedom from human intervention & $\begin{array}{l}\text { Equal treatment in relation } \\
\text { to conservation }\end{array}$ \\
\hline Animals & $\begin{array}{l}\text { Health and functioning } \\
\text { Absence of negative affective states } \\
\text { and allowance of positive ones }\end{array}$ & $\begin{array}{l}\text { Living natural lives and species-specific } \\
\text { behaviors }\end{array}$ & $\begin{array}{l}\text { Equal treatment in relation } \\
\text { to welfare }\end{array}$ \\
\hline People & $\begin{array}{l}\text { Psychological and physiological welfare } \\
\text { Sustainable social, economical, and } \\
\text { cultural welfare }\end{array}$ & $\begin{array}{l}\text { Freedom of choice } \\
\text { Capacity to exercise the various fundamental } \\
\text { aspects of one's own persona } \\
\text { Self-determination }\end{array}$ & Equal and fair treatment \\
\hline
\end{tabular}


and (where applicable) the psychological-combined with the fairness principle. This is done, on the one hand, to reflect the plurality of dimensions in animal welfare, and, on the other hand, to pursue a solid synthesis between them. While dimensions of animal welfare often overlap in terms of goals, single minded adhesion to just one of them leads to an impoverished concept of welfare, and, in this way, to a poor approach to the care of animals (Fraser et al., 1997; Fraser, 2009).

Still, the inclusion of a dedicated space in EM for animal ethics may be objected. It may be said, for instance, that traditional conservation excludes direct interest for the fate of individual animals from its moral compass (Soulé, 1985). On this regard, there is no doubt that conservation and animal welfare are conceptually distinct and usually have distinct goals. In fact, while sometime their agendas may overlap-as it is the case, for instance, of demographic collapse of populations (Beausoleil, 2014), land clearing and other form of habitat destruction (Fraser, 2010; Finn and Stephens, 2017), and animal care in conservation breeding and reintroduction programs (Harrington et al., 2013; Greggor et al., 2018) —in many other occasions they explicitly differ.

Yet, it is precisely for this reason that focusing of animal welfare become important for conservation, as excessive divergence between the goals of conservation and animal welfare may remove societal support for conservation projects (McMahon et al., 2012; Beausoleil et al., 2018). Nonetheless, conservationists should not pursue animal welfare only for realpolitik. Concern for animal welfare per se is indeed an ever more important aspect of conservation (Johnson et al., 2019), as much as animal welfare science growing attention toward wild animals (Littin and Mellor, 2005; Hampton and Hyndman, 2018). However, behind direct ethical reasons, maintaining a high welfare standard is certainly important for the prolonged success of a conservation endeavor.

It should be noted that animal welfare does not equate with animal rights (Perry and Perry, 2008) - if this latter is defined as the position advocating that animals possess a right to live akin to that of humans, and, hence, killing them, except for particular cases such as self-protection, is wrong (Regan, 2004). In fact, the two positions can even clash, as when, for instance no-culling policies worsen the welfare of animals-as in the case of herbivores affected by overpopulation (Hampton et al., 2018; Wilson and Edwards, 2019). The general ethical principles and the value demands inserted in the basic EM for conservation do not support an animal rights view for the reason that the analytical frame of the tool, as noted before, is grounded on common morality. While animal welfare ethics (Fraser, 2008; Rollin, 2015) is as an extension and a refinement of the old and cross-cultural imperative to not be cruel to animals, animal rights stands as a drastic revisionary attempt of common morality, and, as such, is outside the analytical scope of the EM.

It should be moreover noted that inclusion in the EM of animal ethics do not amount to adoption of a biocentric stance. Biocentrism is the view that all living beings deserve moral status, regardless of sentience or of other qualities beyond their being alive (Humphreys, 2016). Like animal ethics, biocentrism is an individualistic and extensionist theory. However, the extension of moral concern it proposes crosses the borders of sentience and even of the animal kingdom-as plants and fungi are alive too-and, possibly, also of the eukaryote domain. The biological "interests" of an organism, according to biocentrists, are as much ethically signifycative as interests born from desires and preferences (Goodpaster, 1978). In this way, even plants should be deemed morally considerable as individuals (Attfield, 1981).

Biocentrism has been criticized for being either too demanding in theory or too incoherent in its applications (Sterba, 1998). Indeed, its extension of the moral domain multiplies unrealistically the possibilities of friction. It is not necessary here to reconstruct the arguments employed by biocentrists to solve the issue by building hierarchies of value within the life domain-thus restoring sentience to a privileged place. Similarly to animal rights, biocentric egalitarianism, in its most radical versions, is a revisionary approach to common morality, and, as such, whatever may be its merits, it does not fit within the frame of the EM.

Biocentrism, however, more than being a mere defense of plants' moral standing, has also been used as a cornerstone to build non-anthropocentric environmental ethics (for instance, Taylor, 2011). In this case, the problem lies in how it is articulated the passage from the respect due to individual living beings to the respect due to "nature" - that is, to biological levels higher or lower than individual organisms. In one sense, this synthesis may lead to an inegalitarian version of biocentrism (Agar, 2001) which support forms of non-anthropocentric environmental value compatible with the frame of the EM. In another sense, it may lead instead to a position at odds with the ecological requirements of environmentalism. Conservation practices usually involve reallocating harms and benefits from some group to another (i.e., invasive species control). If there is no way to discriminate between individual organisms, this reallocation can never be justified (except, perhaps, for anthropocentric reasons), and the only form of acceptable approach to conservation would be benign neglect. However, in our heavily anthropized world, such approach cannot be counted to accomplish much.

In a similar vein, the human dimension in the EM is structured in order to take into account several fundamental aspects. In particular, the ethical frame embedded in the EM is able to accommodate the ethically significant elements coming either from consequentialist and deontological perspectives. These elements, moreover, can be assumed both from an individual or from a group or community level, recognizing the dual nature of social ethics. In this way, the integration of the three principles makes it possible to account for the complexity that the human dimension can assume within conservation.

\section{FILLING IN THE EM FOR CONSERVATION}

The general template provided in Table $\mathbf{1}$ can be used as a starting point for filling more detailed EMs.

In order to follow the robust ethical approach previously described, while filling in an EM, three general goals should be pursued. The first one is completeness. An EM is considered 
complete if it includes all the relevant stakeholder. The second goal is pluralism. An EM is pluralist if it explores the outcomes of all the general ethical principles. The third requirement is neutrality. An EM is neutral if value-demands are acquired by taking into consideration the standpoints of each stakeholder, producing an objective description-devoid of biases and prejudices-as much as possible. These requirement are in line with the general goal of the EM to provide a transparent and inclusive list of the values involved.

The actual process of compiling an EM can follow different methodologies. An EM can be filled through a top-down approach, in which ethical experts draw the specific value demands from the available information. Otherwise, it can be filled trough a bottom-up approach carried out by professionals, experts, and representatives of the various stakeholders coordinated by a facilitator. A third and a fourth methodology combine the previous approaches, by starting bottom-up and then refining top-down, or vice versa. These last two approaches have undoubtedly the advantages of combining both basic methodologies and increasing the pluralism of the final matrix by joining both ethical and hands-on expertise on the matter. This may increase the public legitimacy of the assessment. In fact, single approaches may suffer from partiality when assessing particularly controversial topics-especially the top-down approach, as experts may be value-laden (Forsberg, 2004).

Ideally, the process of compiling the EM should happen at the beginning of the decision making process, during the phase of situation analysis. In the context of adaptive management (Williams et al., 2009), for instance, the EM should be compiled during the process of stakeholders engagement. A first topdown draft of the EM could be prepared during the preliminary assessment of the socio-ecological context, and then be discussed and refined bottom-up during the actual process of stakeholders engagement (Organ et al., 2012). The EM constructed in this way can then be used throughout the subsequent participatory process, especially during objectives setting, identification of impacts, and identification of alternatives. Adaptive management is particularly vulnerable to conflicts between stakeholders (Williams et al., 2009; Keith et al., 2011), and the EM can help anticipating these, and suggesting the implementation of conflict resolution before paralysis is reached. Similarly, in the context of structured decision making (Gregory et al., 2012), the EM, prepared during context analysis may then assist the process of creation and discussion of objectives. In fact, the kind of analysis produced by the EM is aligned with two core principle of structured decision making, that is, separation of values from fact, and value focused thinking.

The process of filling in a specific EM follows three steps:

\section{- Gathering information \\ - Identification of the stakeholders \\ - Identification of the value demands}

In the first step all the relevant information on the case is gathered and evaluated. This is done primarily to clarify the scenario under scrutiny and to highlight the various critical issues it may present. Relevant information may be gathered through various sources, such as scientific literature, gray literature, experts' opinions, media, laws and regulations, data from interviews, surveys and questionnaires, focus groups, and so on.

The second step is to individuate the relevant stakeholders to be included in the EM. As a minimum, an EM should have at least three stakeholders: one to represent the ecological entity targeted by the conservation project, one to represent the impact of the conservation project on overall or local biodiversity, and another to represent the impact on people. Moreover, in every cases when the target of the conservation project includes animals, these should be represented as a fourth stakeholder.

Normally, however, the EM will include more than three or four stakeholders. In general, the ideal number of stakeholders should be enough to include every party involved without making the ethical analysis excessively complex and specific. Moreover, stakeholder should be selected in order to not duplicate unnecessarily the same ethical standpoint. The weight of a certain value demands is not determined by how many times it is repeated in different cells of the EM. However, multiple instance of the same value demands may cause unwanted bias, or simply unnecessarily complicate the analysis. In this sense, it is particular important to not let that stakeholders in the "people" class duplicate value demands already presented in the other two classes. This does not means that the standpoint of conservationists or animal welfare groups should not be included in the EM. Observations from these groups could be crucial in populating the cells for ecological entities and individual animals in a bottom-up process of filling the EM.

In the third step the general ethical principles are applied to each stakeholder in order to specify the basic value demands contained in Table 1. In some cases, some value demands will not fit the nature of a particular stakeholder, and, as such, they should be excluded. The result should recap the framework of moral interests and demands involved in the situation, thus allowing the decision makers to assess the impact of their choices on each specific stakeholder.

Table 2 offers an example of a compiled EM relative to the conservation of the white-clawed crayfish Austropotamobius pallipes, an endangered European freshwater crustacean severely menaced by various human-induced causes such as water abstraction, pollution, and channelization of banks, competition with invasive alien crayfish species, and spreading of the so-called "crayfish plague," an infectious disease whose etiological agent is the oomycete Aphanomyces astaci.

This EM provides an example of the functioning of the tool in a case of real conservation, in which the critical issues that justify the intervention are multiple, as well as the potential conflicts. The level of the analysis is deliberately general: the EM was compiled top-down as a draft for bottomup refinement and contextualization to specific interventions. The list of stakeholders was restricted in order to avoid unnecessary duplications-all non-indigenous crayfish species, for instance, where collected in a single row, as well as all individual crayfish regardless of the species or indigenous status. A general stakeholder for "local communities"-understood as all the human beings living, working, studying, visiting or simply interested in the area where the conservation efforts 


\section{Ecological}

A. Biodiversity

B. White-clawed Conservation of the taxon. The white-clawed crayfish

crayfish (Austropotamobius pallipes-) is presently classified by IUCN as

Non-indigenous crayfish species (NICS)

\section{Animals}

D. Individual Health and functioning. Having access to good living conditions crayfishes (regardless of species) quality water, suitable environments, avoiding overcrowding, etc.
Conservation of richness and variety at all levels. Generally speaking, replacement of native species with non-native species determines overall homogenization of biodiversity, and as such, it should be avoided

Moreover, we should exercise an extra care for the conservation of native keystone species, as their disappearance or replacement could provoke a further loss of biodiversity "Endangered," with a fragmented and decreasing population. Th main extinction drivers are human induced (habitat destruction and modification, competing invasive alien crayfish species, diseases-the "crayfish plague," caused by the oomycete Aphanomyces astaci-carried by alien crayfish species)

Conservation of the taxon depends on several human intenvention in Conservation of the taxon dep ds on several human intervention. particular, conseris populations in order to avoid furher genetic inpovenishont; restricting interventions on rivers and streams inhabited by the species, especially by reducing or eliminating water depletion, modification of riverbeds and banks, and spillage of wastewater, providing means of connection between the fragmented populations; focused re-introductions in appropriate sites; avoiding the spreading of NICS (and outbreaks of $A$. astaci) by means of population control and barriers; avoiding accidental introduction of $A$. astaci in sites; contrast of poaching; containment of competitors (by avoiding, for instance, introduction of predator species); periodical monitoring of the sites; promoting conservation education

Conservation of the taxa. No NICS is presently at risk of extinction. Hence, no actions are needed to is presently at risk of extinction. range

Outside their native range no conservation value is attached to the presence of NICS

Freedom from human intervention. Conservation efforts should not compromise the naturalness of the areas where they occur

Freedom from human intervention. Conservation obstinacy should be avoided meaning that some populations could be simply not possible to conserve, and some sites could be simply not possible to repopulate

Even when interventions are deemed likely to succeed we stil should exercise caution, especially concerning

reintroductions and re populations. For ining entaptations to

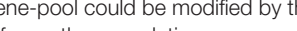
loc

Freedom from human intervention. Nature is not fixed and unchanging. Species have always got ahead of others, colonized new territories, and replaced "natives." Every species should have a certain freedom to expand beyond its native range, even if it comes at expense of other species. However, spreading of NICS outside their native areat can. be assimilated to the natural process of interspecific competition, as it is artificially caused by human voluntary or involuntary intervention

Health and functioning. Having access to good living conditions fisheries,
Freedom of choice. Self-determination. Having access to an environment sufficiently not degraded (if in the wild) or enough enriched (if kept captive) to be capable to express the standard behavioral repertoire
Respect for the worth of every component. Some species, including NICS, may be better suited to ou economic and recreational interests than other. Nevertheless, we should consider the effects the have on other taxa, and the overall biodiversity homogenization and impoverishment they cause

Respect for the worth of the taxon. In the current context, A. pallipes has little sustainable economic and recreational value. Past claims that it could be a good bioindicator of water quality have been scaled down. It has some limited potential as a flagship and umbrella species, and it can considered a heritage umbrela species, andit can considered a heritage keystone species

Howeve, whace the species' overall appeal could he, we should still be, we should still consider it important to presenve or its existence value

Respect for the worth of the taxon. Invasive alien species (IAS) replace indigenous species, cause biodiversity loss, introduce new diseases and zoonoses, and can provoke economic damages. However, not every non-indigenous species can be automatically classified an IAS. Furthermore, NICS aut could have postive qualties that could -at leas part-soften our evaluation. They could be, for Finally, the same con Finally, the same concept of "non-inaligenous" goes beyond "bein scientific defintions, and can be also tied to "bening a recognzed part of a landscape." In this regard, it is worth remembering that non-indigenous species can quickly become a "recognized part of the landscape" of people - as the red swamp crayfish (Procambarus clarkii-) is, for instance, in some parts of Spain. Such recognization may not become evident until the species is perceived to be threatened, and, as such, can come as a surprise to conservationists

Respect for the worth of every individual.

Crustaceans, like most invertebrates, receive scarce empathy. This should not prevent us to treat crayfish in a humane way - when manipulating them, and especially when killing them 


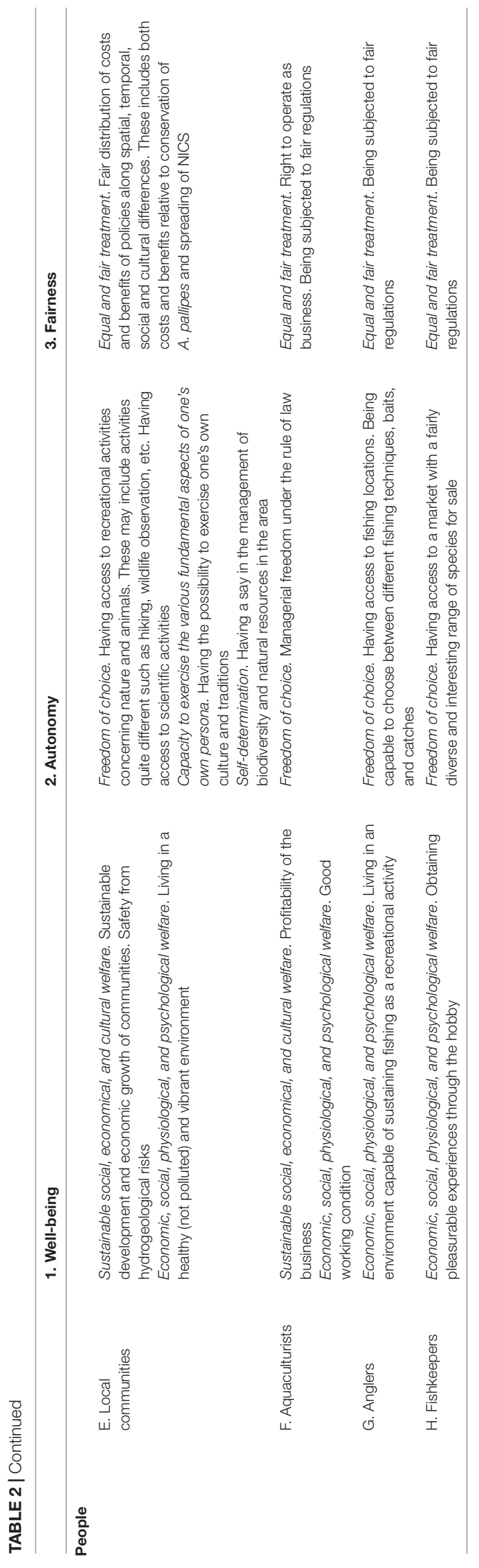

are taking place-was included, with the implicit assumptions that more contextualized analyses should unpack it according to the specific group dynamics of the scenario under scrutiny (Waylen et al., 2013). Three other general human stakeholder were individuated by looking at the principal extinction drivers of A. pallipes-aquaculturists, anglers, and fishkeepers. These latter three categories are possible vectors for the introduction of invasive crayfish species and crayfish plague, and, as such, their interests need to be included in order to have a full picture of the conservation scenario for A. pallipes.

The EM was populated first by applying the general ethical principles to each stakeholders, as per Table 1. Then, this draft was expanded by specifying each value demands. Each value demand was left enough open in order to be further specified in a bottom-up process of refinement.

\section{AFTER THE EM FOR CONSERVATION IS FILLED}

\section{Situation Analysis}

The filled matrix should produce an overall picture of the values involved in the scenarios. The EM, with its default inclusion of certain categories of stakeholders and ethical principles, should provide to this overall picture a certain minimum threshold of pluralism and completeness (Schroeder and Palmer, 2003). Moreover, the use of general ethical principles and adherence to common morality should allow for anticipating the actual claims and demands that could be advocated by active and passive parties in the scenario. In this sense, use of the EM has been found to increase the capacity for building a reliable ethical analysis even without direct involvement of stakeholders (Jensen et al., 2011).

At the same time, however, another advantage of the approach is that it is also suitable to be used in participatory processes with actual representatives of the stakeholders (Kaiser and Forsberg, 2001; Kaiser et al., 2007). The peculiar frame of the EM, in this case, helps making more down to earth abstract ethical principles to people who may have a low grip or interest in ethical theory as such. Moreover, it does not constrain the participants into the boundaries of a single specific ethical theory or single ethical perspectives, but tries instead to account for different angles. This can prevent stakeholders from feeling left out during the participatory process, avoiding in this way a first possibility for conflicts.

The plurality of ethical perspectives that the EM is capable of implementing should be evident from Table 2. Concerning ecological entities, the matrix is able to structure its analysis at different biological levels, and around different modes of value (instrumental, non-instrumental). Concerning individual animals, the EM is able to account for the complexity and multidimensionality of animal welfare. Concerning people, the matrix is able to distinguish between different levels of aggregation, and anticipate interests and claims from different angles (justice, freedom, equity, safety, etc.).

The filled EM can fulfill many tasks. It provides, for instance, a moral checklist, recapping to the decision-maker all the ethically relevant aspects involved in the case. In this way, it can be used 
as a starting point for structured discussion in the participatory process, and as a guide during the debate, in order to not neglect some ethically relevant issues. This may become especially important at the later stages of a decision making process. Some values-such, for instance, existence or heritage value of species-are hard to quantify and end up being overlooked during the phase when trade-off are discussed and proposed (Law et al., 2018). Use of the EM as a checklist of prima facie moral demands can help not to lose sight of these values during all the later stages of the process, and to detect non-compliance. In this regard, one of the merits of the EM is to make the values at stakes explicit, enhancing in this way the transparency of the decision making process.

As shown in the example presented in Table 2, all interests are listed-even those that are not quantifiable (like existence value of the endangered species), seemingly marginal (possibility that alien species become recognized by people as a part of their landscape) or that clearly clash with conservation needs, and must therefore be scaled and balanced in some way (such as fishkeepers' freedom of choice).

It is worth noting that, while transparency does not guarantee success when stakeholders do not share a common ethical ground, it remains nevertheless a crucial goal to be pursued (Ford et al., 2021). An incomplete or opaque communication is liable to be contested, can fuel mistrust in stakeholders already inclined to look at the conservation projects with suspicion, and may even alienate the favors of those who shared instead a neutral or positive attitude (Crowley et al., 2017). Transparent communication and willingness to examine different viewpoints are necessary components of participatory decision making (Addison et al., 2013): the EM can help with both.

\section{Conflict Analysis}

Another standard use of the EM is to reveal ethical conflicts and ethical issues not addressed in-depth (Kermisch and Depaus, 2018). More specifically, the filled EM can to be used to anticipate conflicts between stakeholders, as it makes clear which pairs or groups of value demands are difficult or simply impossible to be satisfied simultaneously. For instance, in the example contained in Table 2, several cells of the EM contain conflicting value demands, giving raise to two sets of conflicts:

- Conservation action in favor of $A$ pallipes vs. (a) avoidance of conservation obstinacy; (b) spreading of non-indigenous crayfish species; (c) safeguard of individual crayfish; (d) certain human interests.

- Spreading of non-indigenous crayfish species vs. (a) biodiversity protection; (b) certain human interests.

The map of value conflicts provides the decision maker with a starting point for conflict analysis and resolution. This may happen through different forms of intervention.

A first form of intervention could be ranking the conflicts through their logical order-that is, through the order they should be analyzed. In the example contained in Table 2, conflicts relative to spreading of non-indigenous crayfish species vs. biodiversity protection and human interests should be analyzed first, as they could bring important elements to add to the scenario. Direct intervention in favor of $A$. pallipes, for instance, whereas difficult to ground in front of competing value demands, could nevertheless be justified indirectly due to the friction exercised by the invasive non-indigenous species on human interests or other aspects of biodiversity. At the same time, the necessity of controlling the invasive populations could raise new conflicts due to the interests of particular group of people (like, for instance, fishkeepers, anglers, or aquaculturists) - and so on.

A second form of intervention could be classification of conflicts. Values are often distinguished in two broad categories: "secular," meaning that they are commensurable and can be traded-off, and sacred, meaning that they are not commensurable as nothing proper can compensate for their loss (Tetlock et al., 2000). Value conflicts, hence, can be of three kinds: between (a) two secular values; (b) a secular and a sacred values; (c) two sacred values. Conflicts of the first kind are usually easily resolved. Conflicts of the second kind-so called "taboo conflicts"elicit instead repugnance, and people may be psychologically uncomfortable even to think about them, as the prospective of "selling away" a non-commensurable value may cause indignation and moral outrage (Tetlock, 2003). Finally, conflict of the third kind-so called "tragic conflicts" - while clearly not easy to resolve, are not considered repugnant, and careful ponderation may reduce controversy surrounding their eventual resolution (Schoemaker and Tetlock, 2012).

Literature on conflicts in conservation focusing on the psychology and the neuroscience of moral conflicts like the "trolley problem" has confirmed this subdivision (Can and Macdonald, 2018; Schwartz, 2020). In particular, negotiating or even discussing taboo conflicts between stakeholders seems to be rather difficult, while resolution of tragic conflicts, even if accompanied by less controversy, is usually dictated by a preference for the passive course of action and status quo. Recognizing in time taboo and tragic conflicts become then really important for the success of a conservation projects. Anticipating taboo conflicts, for instance, permits to devise the necessary strategies for avoiding deadlocks or loss of support by stakeholders, either by devising alternative interventions, or by reframing conflicts in the more acceptable standard or tragic frames (Daw et al., 2015).

\section{CONCLUSION}

Acting in conservation today implies carefully considering the consequences of our choices. It also entails engaging in transparent forms of communication, and being able to explain and give reasons for decisions and policies which can have an ethical impact on people, animals and the environment. The EM can help conservationists in reaching these objectives rigorously.

Anticipating value conflicts can help also in early intervention to avoid polarization (Crowley et al., 2017). Polarization occurs when conflicts between stakeholders comes to be defined in 
binary terms, and eventual areas of agreement are overlooked. In this way, the whole scenario becomes framed as a win or lose game, with either side forced to not to give up ground until stalemate is reached, or one of the participants leaves the table-usually only to escalate the conflict at a higher level.

A detailed map of conflicts can also assist in the process of designing possible trade-off, by anticipating possible impacts on the stakeholders and suggesting fair solutions. It is important to remind, however, that a filled EM does not remove the need for a decision maker: the EM is a descriptive tool, not a "decision making algorithm" to deduce specific conclusions. Its value in this sense, is to offer a clear method to collect all the value demands involved in a complex case and organize them in a complete, pluralist and neutral framework

\section{REFERENCES}

Addison, P. F. E., Rumpff, L., Bau, S. S., Carey, J. M., Chee, Y. E., Jarrad, F. C., et al. (2013). Practical solutions for making models indispensable in conservation decision-making. Divers. Distrib. 19, 490-502. doi: 10.1111/ddi. 12054

Agar, N. (2001). Life's Intrinsic Value. Science, Ethics, and Nature. New York, NY: Columbia University Press.

Amori, G., and Gippoliti, S. (2000). What do mammalogists want to save? Ten years of mammalian conservation biology. Biodivers. Conserv. 9, 785-793. doi: 10.1023/A:1008971823774

Attfield, R. (1981). The good of trees. J. Value Inq. 15, 35-54.

Batavia, C., and Nelson, M. P. (2017). For goodness sake! What is intrinsic value and why should we care? Biol. Conserv. 209, 366-376. doi: 10.1016/j.biocon. 2017.03.003

Beauchamp, T. L. (2010). Standing on Principles. Oxford: Oxford University Press.

Beauchamp, T. L., and Childress, J. F. (1985). Principles of Biomedical Ethics. Oxford: Oxford University Press.

Beauchamp, T. L., and DeGrazia, D. (2004). "Principles and Principlism," in Handbook of Bioethics, ed. G. Khushf (Dordrecht: Springer).

Beauchamp, T. L., and Rauprich, O. (2016). "Principlism," in Encyclopedia of Global Bioethics, ed. H. ten Have (Cham: Springer).

Beausoleil, N. J. (2014). "Balancing the need for conservation and the welfare of individual animals," in Dilemmas in Animal Welfare, eds M. C. Appleby, D. M. Weary, and P. Sandøe (Wallingford: CABI).

Beausoleil, N. J., Mellor, D. J., Baker, L., Baker, S. E., Bellio, M., Clarke, A. S., et al. (2018). "Feelings and fitness" Not "Feelings or fitness"-The Raison d'être of conservation welfare, which aligns conservation and animal welfare objectives. Front. Vet. Sci. 5:296. doi: 10.3389/fvets.2018.00296

Bertolino, S., and Genovesi, P. (2003). Spread and attempted eradication of the grey squirrel (Sciurus carolinensis) in Italy, and consequences for the red squirrel (Sciurus vulgaris) in Eurasia. Biol. Conserv. 109, 351-358. doi: 10.1016/s00063207(02)00161-1

Biasetti, P., and de Mori, B. (2016). A framework of values: reasons for conserving biodiversity and natural environments. Etica. Polit. 18, 527-545.

Biasetti, P., and de Mori, B. (2020). Towards a conservation ethics. Iride 33, 471-486. doi: 10.1414/100153

Biasetti, P., Ferrante, L., Bonelli, M., Manenti, R., Scaccini, D., and de Mori, B. (2021). Value-conflicts in the conservation of a native species: a case study based on the endangered white-clawed crayfish in Europe. Rend. Lincei Sci. Fis. Nat. doi: 10.1007/s12210-021-00987-1

Biasetti, P., Florio, D., Gili, C., and de Mori, B. (2020). The ethical assessment of touch pools in aquariums by means of the ethical matrix. J. Agric. Environ. Ethics 33, 337-353. doi: 10.1007/s10806-020-09823-2

Bracke, M. B. M., and Hopster, H. (2006). Assessing the importance of natural behavior for animal welfare. J. Agric. Environ. Ethics 19, 77-89. doi: 10.1007/ s10806-005-4493-7

Bremer, S., Millar, K., Wright, N., and Kaiser, M. (2015). Responsible technoinnovation in aquaculture: employing ethical engagement to explore attitudes that can be consulted by the participant in the decision making process.

\section{AUTHOR CONTRIBUTIONS}

Both authors listed have made a substantial, direct and intellectual contribution to the work, and approved it for publication.

\section{FUNDING}

This work was supported by Barbara de Mori's MIUR DOR funds.

to GM salmon in Northern Europe. Aquaculture 437, 370-381. doi: 10.1016/j. aquaculture.2014.12.031

Callicott, J. B. (1989). In Defense of Land Ethic: Essays in Environmental Philosophy. New York, NY: SUNY Press.

Can, ÖE., and Macdonald, D. W. (2018). Looking under the bonnet of conservation conflicts: can neuroscience help? Biodivers. Conserv. 27, 2087-2091. doi: 10. 1007/s10531-018-1514-1

Catalano, A. S., Lyons-White, J., Mills, M. M., and Knight, A. T. (2019). Learning from published project failures in conservation. Biol. Conserv. 238:108223. doi: 10.1016/j.biocon.2019.108223

Chan, K. M. A., Balvanera, P., Benessaiah, K., Chapman, M., Díaz, S., GómezBaggethun, E., et al. (2016). Why protect nature? Rethinking values and the environment. Proc. Natl. Acad. Sci. U. S.A. 113, 1462-1465. doi: 10.1073/pnas. 1525002113

Chan, K. M. A., Pringle, R. M., Ranganathan, J., Boggs, C. L., Chan, Y. L., Ehrlich, P. R., et al. (2007). When agendas collide: human welfare and biological conservation. Conserv. Biol. 21, 59-68. doi: 10.1111/j.1523-1739.2006.0 0570.x

Colléony, A., Clayton, S., Couvet, D., Saint Jalme, M., and Prévot, A. C. (2017). Human preferences for species conservation: animal charisma trumps endangered status. Biol. Conserv. 206, 263-269. doi: 10.1016/j.biocon.2016.11. 035

Cotton, M. (2009). Evaluating the "Ethical Matrix" as a radioactive waste management deliberative decision-support tool. Environ. Values 18, 153-176. doi: 10.3197/096327109x438044

Courchamp, F., Jaric, I., Albert, C., Meinard, Y., Ripple, W. J., and Chapron, G. (2018). The paradoxical extinction of the most charismatic animals. PLoS Biol. 16:e2003997. doi: 10.1371/journal.pbio.2003997

Crowley, S. L., Hinchliffe, S., and McDonald, R. A. (2017). Conflict in invasive species management. Front. Ecol. Environ. 15, 133-141. doi: 10.1002/fee. 1471

Daw, T. M., Coulthard, S., Cheung, W. W. L., Brown, K., Abunge, C., Galafassi, D., et al. (2015). Evaluating taboo trade-offs in ecosystems services and human well-being. Proc. Natl. Acad. Sci. U. S. A. 112, 6949-6954. doi: 10.1073/pnas. 1414900112

de Mori, B., Ferrante, L., Florio, D., Macchi, E., Pollastri, I., Normando, S., et al. (2019). A protocol for the ethical assessment of wild AnimalVisitor Interactions (AVIP) evaluating animal welfare, education, and conservation outcomes. Animals 9:487. doi: 10.3390/ani908 0487

England, G. C. W., and Millar, K. M. (2008). The ethics and role of AI with fresh and frozen semen in dogs. Reprod. Domest. Anim. 43, 165-171. doi: 10.1111/j.1439-0531.2008.01157.x

Finn, H. C., and Stephens, N. S. (2017). The invisible harm: land clearing is an issue of animal welfare. Wildl. Res. 44, 377-391. doi: 10.1071/ wr17018

Ford, A. T., Ali, A. H., Colla, S. R., Cooke, S. J., Lamb, C. T., Pittman, J., et al. (2021). Understanding and avoiding misplaced efforts in conservation. FACETS 6:252-271. doi: 10.1139/facets-2020-0058 
Forsberg, E. M. (2004). The ethical matrix-a tool for ethical assessments of biotechnology. Glob. Bioeth. 17, 167-172. doi: 10.1080/11287462.2004. 10800856

Fraser, D. (2008). Understanding Animal Welfare. Oxford: Wiley-Blackwell.

Fraser, D. (2009). Assessing animal welfare: different philosophies, different scientific approaches. Zoo. Biol. 28, 507-518. doi: 10.1002/zoo.20253

Fraser, D. (2010). Toward a synthesis of conservation and animal welfare science. Anim. Welf. 19, 121-124.

Fraser, D., Weary, D. M., Pajor, E. A., and Milligan, B. N. (1997). A scientific conception of animal welfare that reflects ethical concerns. Anim. Welf. 6, 187-205.

Gamborg, C. (2002). The acceptability of forest management practices: an analysis of ethical accounting and the ethical matrix. For. Policy Econ. 4, 175-186. doi: 10.1016/s1389-9341(02)00007-2

Goodpaster, K. E. (1978). On being morally considerable. J. Philos. 75, 308-325. doi: $10.2307 / 2025709$

Greggor, A. L., Vicino, G. A., Swaisgood, R. R., Fidgett, A., Brenner, D., Kinney, M. E., et al. (2018). Animal welfare in conservation breeding: applications and challenges. Front. Vet. Sci. 5:323. doi: 10.3389/fvets.2018.0 0323

Gregory, R., Failing, L., Harstone, M., Long, G., McDaniels, T., and Ohlson, D. (2012). Structured Decision Making. A Practical Guide to Environmental Management Choices. Chichester: Wiley-Blackwell.

Hampton, J. O., and Hyndman, T. H. (2018). Underaddressed animal-welfare issues in conservation. Conserv. Biol. 33, 803-811. doi: 10.1111/cobi. 13267

Hampton, J. O., Warburton, B., and Sandøe, P. (2018). Compassionate versus consequentialist conservation. Conserv. Biol. 33, 751-759. doi: 10.1111/cobi. 13249

Harrington, L. A., Moehrenschlager, A., Gelling, M., Atkinson, R. P. D., Hughes, J., and Macdonald, D. W. (2013). Conflicting and complementary ethics of animal welfare considerations in reintroductions. Conserv. Biol. 27, 486-500. doi: $10.1111 /$ cobi.12021

Howard, B. J., Beresford, N. A., Nisbet, A., Cox, G., Oughton, D. H., Hunt, J., et al. (2005). The strategy project: decision tools to aid sustainable restoration and long-term management of contaminated agricultural ecosystems. J. Environ. Radioact. 83, 275-295. doi: 10.1016/j.jenvrad.2005.01.013

Humphreys, R. (2016). "Biocentrism," in Encyclopedia of Global Bioethics, ed. H. ten Have (Cham: Springer).

Jamieson, D. (2008). Ethics and the Environment. An Introduction. Cambridge: Cambridge University Press.

Jarić, I., Courchamp, F., Correia, R. A., Crowley, S. L., Essl, F., Fischer, A., et al. (2020). The role of species charisma in biological invasions. Front. Ecol. Environ. 18, 345-353. doi: 10.1002/fee.2195

Jensen, K. K., Forsberg, E. M., Gamborg, C., Millar, K., and Sandøe, P. (2011). Facilitating ethical reflection among scientists using the ethical matrix. Sci. Eng. Ethics 17, 425-445. doi: 10.1007/s11948-010-9218-2

Johnson, P. J., Adams, V. M., Armstrong, D. P., Baker, S. E., Biggs, D., Boitani, L., et al. (2019). Consequences matter: compassion in conservation means caring for individuals, populations and species. Animals 9:1115. doi: 10.3390/ ani9121115

Justus, J., Colyvan, M., Regan, H., and Maguire, L. (2009). Buying into conservation: intrinsic versus instrumental value. Trends Ecol. Evol. 24, 187191. doi: $10.1016 /$ j.tree.2008.11.011

Kaiser, M., and Forsberg, E. M. (2001). Assessing fisheries - using an ethical matrix in a participatory process. J. Agric. Environ. Ethics 14, 191-200. doi: 10.1023/A:1011300811590

Kaiser, M., Millar, K., Thorstensen, E., and Tomkins, S. (2007). Developing the ethical matrix as a decision support framework: GM fish as a case study. J. Agric. Environ. Ethics 20, 65-80. doi: 10.1007/s10806-006-9023-8

Keith, D. A., Martin, T. G., McDonald-Madden, E., and Walters, C. (2011). Uncertainty and adaptive management for biodiversity conservation. Biol. Conserv. 144, 1175-1178. doi: 10.1016/j.biocon.2010. 11.022

Kermisch, C., and Depaus, C. (2018). The strength of ethical matrixes as a tool for normative analysis related to technological choices: the case of geological disposal for radioactive waste. Sci. Eng. Ethics 24, 29-48. doi: 10.1007/s11948017-9882-6
Krause, M., and Robinson, K. (2017). Charismatic species and beyond: how cultural schemas and organisational routines shape conservation. Conserv. Soc. 15, 71-79. doi: 10.4103/cs.cs_16_63

Law, E. A., Bennet, N. J., Ives, C. D., Friedman, R., Davis, K. J., Archibald, C., et al. (2018). Equity trade-offs in conservation decision making. Conserv. Biol. 32, 294-303. doi: 10.1111/cobi.13008

Littin, K. E., and Mellor, D. J. (2005). Strategic animal welfare issues: ethical and animal welfare issues arising from the killing of wildlife for disease control and environmental reasons. OIE Rev. Sci. Tech. 24, 767-782. doi: 10.20506/rst.24.2. 1611

Mammola, S., Riccardi, N., Prié, V., Correia, R., Cardoso, P., Lopes-Lima, M., et al. (2020). Towards a taxonomically unbiased EU biodiversity strategy for 2030 . Proc. Biol. Sci. 287:20202166. doi: 10.1098/rspb.2020.2166

McMahon, C. R., Harcourt, R., Bateson, P., and Hindell, M. A. (2012). Animal welfare and decision making in wildlife research. Biol. Conserv. 153, 254-256. doi: 10.1016/j.biocon.2012.05.004

McShane, T. O., Hirsch, P. D., Trung, T. C., Songorwa, A. N., Kinzig, A., Monteferri, B., et al. (2011). Hard choices: making trade-offs between biodiversity conservation and human well-being. Biol. Conserv. 144, 966-972. doi: 10.1016/j.biocon.2010.04.038

Mepham, B. (1996). Food Ethics. New York, NY: Routledge.

Millar, K. (2013). "Ethics and ethical analysis in veterinary science: the development and application of the ethical matrix method," in Veterinary \& Animal Ethics. Veterinary \& Animal Ethics, eds C. M. Wathes, S. A. Corr, S. A. May, S. P. McCulloch, and M. C. Whiting (Oxford: Wiley-Blackwell).

Millar, K., and Tomkins, S. (2007). Ethical analysis of the use of gm fish: emerging issues for aquaculture development. J. Agric. Environ. Ethics 20, 437-453. doi: 10.1007/s10806-007-9051-z

Minteer, B. A., and Collins, J. P. (2005a). Why we need an "Ecological Ethics." Front. Ecol. Environ. 3:332. doi: 10.1890/1540-92952005003[0332:WWNAEE] 2.0.CO;2

Minteer, B. A., and Collins, J. P. (2005b). Ecological ethics: building a new tool kit for ecologists and biodiversity managers. Conserv. Biol. 19, 1803-1812. doi: 10.1111/j.1523-1739.2005.00281.x

Minteer, B. A., and Collins, J. P. (2008). From environmental to ecological ethics: toward a practical ethics for ecologists and conservationists. Sci. Eng. Ethics 14, 483-501. doi: 10.1007/s11948-008-9087-0

Norton, B. G. (1991). Toward Unity Among Environmentalists. New York: Oxford University Press.

Organ, J. F., Decker, D. J., Riley, S. J., and Mahoney, S. P. (2012). "Adaptive management in wildlife conservation," in The Wildlife Techniques Manual, ed. N. J. Silvy (Baltimore: The Johns Hopkins University Press).

Perry, D., and Perry, G. (2008). Improving interactions between animal rights groups and conservation biologists. Conserv. Biol. 22, 27-35. doi: 10.1111/j. 1523-1739.2007.00845.x

Peterson, R. B., Russell, D., West, P., and Brosius, J. P. (2010). Seeing (and doing) conservation through cultural lenses. Environ. Manage. 45, 5-18. doi: 10.1007/ s00267-008-9135-1

Piccolo, J. J., Washington, H., Kopnina, H., and Taylor, B. (2018). Why conservation scientists should re-embrace their ecocentric roots. Conserv. Biol. 32, 959-961. doi: 10.1111/cobi.13067

Regan, T. (2004). The Case For Animal Rights. Updated With a New Preface. Berkeley, CA: University of California Press.

Reid, W. V., Mooney, H. A., Capistrano, D., Carpenter, S. R., Chopra, K., Cropper, A., et al. (2006). Nature: the many benefits of ecosystem services. Nature 443:749. doi: $10.1038 / 443749$ a

Rollin, B. E. (2006). Animal Rights \& Human Morality, Third Edn. New York, NY: Prometheus Book.

Rollin, B. E. (2015). The inseparability of science and ethics in animal welfare. J. Agric. Environ. Ethics 28, 759-765. doi: 10.1007/s10806-015-9558-7

Schoemaker, P. J. H., and Tetlock, P. E. (2012). Taboo scenarios: how to think about the unthinkable. Calif. Manage. Rev. 54, 5-24. doi: 10.1525/cmr.2012.54.2.5

Schroeder, D., and Palmer, C. (2003). Technology assessment and the "Ethical Matrix." Poiesis. Prax. 1, 295-307. doi: 10.1007/s10202-003-0027-4

Schwartz, M. W. (2020). Conservation lessons from taboos and trolley problems. Conserv. Biol. doi: 10.1111/cobi.13618 [Epub ahead of print]

Soulé, M. E. (1985). What is conservation biology? Bioscience 35, 727-734. doi: 10.2307/1310054 
Sterba, J. P. (1998). A biocentrist strikes back. Environ. Ethics 20, 361-376. doi: 10.5840 /enviroethics 19982044

Tallis, H., and Lubchenco, J. (2014). Working together: a call for inclusive conservation. Nature 515, 27-28. doi: 10.1038/515027a

Taylor, P. W. (2011). Respect for Nature. A Theory of Environmental Ethics. 25th Anniversary Edition. Princeton, NJ: Princeton University Press.

Tetlock, P. E. (2003). Thinking the unthinkable: sacred values and taboo cognitions. Trends Cogn. Sci. 7, 320-324. doi: 10.1016/s1364-6613(03)00135-9

Tetlock, P. E., Kristel, O. V., Elson, S. B., Green, M. C., and Lerner, J. S. (2000). The psychology of the unthinkable: taboo trade-offs, forbidden base rates, and heretical counterfactuals. J. Pers. Soc. Psychol. 78, 853-870. doi: 10.1037/00223514.78.5.853

Vucetich, J. A., Burnham, D., Macdonald, E. A., Bruskotter, J. T., Marchini, S., Zimmermann, A., et al. (2018). Just conservation: what is it and should we pursue it? Biol. Conserv. 221, 23-33. doi: 10.1016/j.biocon.2018.02.022

Waylen, K. A., Fischer, A., McGowan, P. J. K., and Milner-Gulland, E. J. (2013). Deconstructing community for conservation: why simple assumptions are not sufficient. Hum. Ecol. 41, 575-585. doi: 10.1007/s10745-013-9594-8
Williams, B. K., Szaro, R. C., and Shapiro, C. D. (2009). Adaptive Management: The U.S. Department of the Interior Technical Guide. Adaptive Management Working Group. Washington, DC: Department of the Interior.

Wilson, G. R., and Edwards, M. (2019). Professional kangaroo population control leads to better animal welfare, conservation outcomes and avoids waste. Aust. Zool. 40, 181-202. doi: 10.7882/az.2018.043

Conflict of Interest: The authors declare that the research was conducted in the absence of any commercial or financial relationships that could be construed as a potential conflict of interest.

Copyright (๑) 2021 Biasetti and de Mori. This is an open-access article distributed under the terms of the Creative Commons Attribution License (CC BY). The use, distribution or reproduction in other forums is permitted, provided the original author(s) and the copyright owner(s) are credited and that the original publication in this journal is cited, in accordance with accepted academic practice. No use, distribution or reproduction is permitted which does not comply with these terms. 